\title{
MECHANICAL BEHAVIOUR OF COMPOSITE MATERIALS MADE BY RESIN FILM INFUSION
}

\author{
C. Barile, C. Casavola ${ }^{a}$, C. Pappalettere, F. Tursi \\ Politecnico di Bari - Dept. Ingegneria Meccanica e Gestionale - Viale Japigia, 182 - BARI (Italy)
}

\begin{abstract}
Innovative composite materials are frequently used in designing aerospace, naval and automotive components. In the typical structure of composites, multiple layers are stacked together with a particular sequence in order to give specific mechanical properties. Layers are organized with different angles, different sequences and different technological process to obtain a new and innovative material. From the standpoint of engineering designer it is useful to consider the single layer of composite as macroscopically homogeneous material. However, composites are non homogeneous bodies. Moreover, layers are not often perfectly bonded together and delamination often occurs. Other violations of lamination theory hypotheses, such as plane stress and thin material, are not unusual and in many cases the transverse shear flexibility and the thickness-normal stiffness should be considered. Therefore the real behaviour of composite materials is quite different from the predictions coming from the traditional lamination theory. Due to the increasing structural performance required to innovative composites, the knowledge of the mechanical properties for different loading cases is a fundamental source of concern. Experimental characterization of materials and structures in different environmental conditions is extremely important to understand the mechanical behaviour of these new materials. The purpose of the present work is to characterize a composite material developed for aerospace applications and produced by means of the resin film infusion process (RFI). Different tests have been carried out: tensile, open-hole and filled-hole tensile, compressive, openhole and filled-hole compressive. The experimental campaign has the aim to define mechanical characteristics of this RFI composite material in different conditions: environmental temperature, Hot/Wet and Cold.
\end{abstract}

a E-mail : casavola@poliba.it

This is an Open Access article distributed under the terms of the Creative Commons Attribution-Noncommercial License 3.0, which permits unrestricted use, distribution, and reproduction in any noncommercial medium, provided the original work is properly cited. 